\title{
DID THE 2001 TAX REBATE STIMULATE SPENDING? EVIDENCE FROM TAXPAYER SURVEYS
}

\author{
Matthew D. Shapiro \\ Joel Slemrod \\ Working Paper 9308 \\ http://www.nber.org/papers/w9308 \\ NATIONAL BUREAU OF ECONOMIC RESEARCH \\ 1050 Massachusetts Avenue \\ Cambridge, MA 02138 \\ October 2002
}

We are grateful to Peter Katuscak and Hui Shan for expert research assistance. The Survey Research Center and Office of Tax Policy Research at the University of Michigan supported data collection for this project. The views expressed herein are those of the authors and not necessarily those of the National Bureau of Economic Research.

(C) 2002 by Matthew D. Shapiro and Joel Slemrod. All rights reserved. Short sections of text, not to exceed two paragraphs, may be quoted without explicit permission provided that full credit, including $\odot$ notice, is given to the source. 
Did The 2001 Tax Rebate Stimulate Spending? Evidence From Taxpayer Surveys

Matthew D. Shapiro

Joel Slemrod

NBER Working Paper No. 9308

October 2002

JEL No. E21, H31

\title{
ABSTRACT
}

In 2001, many households received rebate checks as advanced payments of the benefit of the new, 10 percent federal income tax bracket. A survey conducted at the time the rebates were mailed finds that few households said that the rebate led them mostly to increase spending. A follow-up survey in 2002, as well as a similar survey conducted after the attacks of $9 / 11$, also indicates low spending rates. This paper investigates the robustness of these survey responses and assesses whether such surveys are useful for policy evaluation. It also draws lessons from the surveys for macroeconomic analysis of the tax rebate.

\author{
Matthew D. Shapiro \\ Department of Economics \\ University of Michigan \\ Ann Arbor, MI 48109-1220 \\ and NBER \\ shapiro@umich.edu
}

Joel Slemrod

Department of Economics

University of Michigan

Ann Arbor, MI 48109-1220 and NBER

jslemrod@umich.edu 


\section{Introduction}

\subsection{Motivation}

As part of the ten-year tax cut bill passed by Congress in the spring of 2001, tax rebate checks of as much as $\$ 600$ were mailed to American households beginning in late July and continuing until late September. Although not originally conceived of as an antirecessionary policy, by the spring of 2001 this was one of the justifications for the tax cut and for delivering part of the tax cut in this visible form.

According to the standard Keynesian model, the tax rebate would be more effective, the greater the amount of consumption increase it generated. How effective was it? The Bush administration certainly claimed that it was effective in providing a substantial short-run stimulus to the economy. According to a Council of Economic Advisers white paper released in early 2002, it "provided valuable stimulus to economic activity in the short run. The quick enactment last year of the President's tax relief plan softened the recessionary headwinds in 2001 and has helped to put the economy on the road to recovery in 2002."

This paper has three objectives. First, we review survey evidence regarding how effective the tax rebate was in generating consumption and thereby potentially countering an incipient recession. We focus on the results of three consumer surveys, one conducted while the rebates were being received, one conducted for a separate group of people concerning a hypothetical, temporary rebate, and a third conducted six months later in which there is significant overlap of respondents with the first survey. Second, we address the reliability of consumer survey evidence, and how it squares with other macroeconomic indicators of the effectiveness of the tax rebate. Finally, we assess how our survey evidence on the spending rate of the tax rebate bears on estimates of the shortrun aggregate impact of the 2001 policy. 


\subsection{The 2001 Tax Rebate ${ }^{1}$}

Under the Economic Growth and Tax Relief Reconciliation Act of 2001, taxpayers were entitled to a rebate in tax year 2001 of up to $\$ 300$ for single individuals and up to $\$ 600$ in the case of a married couple filing a joint return. Most taxpayers received this payment in the form of a check issued by the Department of the Treasury. These checks were sent out beginning the week of July 23, 2001, and continued until the week of September 24, 2001. Which week a taxpayer received the check depended on the second-to-last digit of their Social Security number.

The tax rebate that we study corresponded to a new 10 percent income tax bracket for a portion of taxable income that was previously taxed at 15 percent, effective for taxable years beginning January 1, 2001. The tax rebate scheme was designed to deliver the benefit of the new 10 percent income tax rate in a highly visible way during calendar year 2001. The 10 percent bracket applied to the first $\$ 6,000$ of taxable income for single individuals, $\$ 10,000$ of taxable income for heads of household, and $\$ 12,000$ for married couples filing joint returns. Thus, the maximum rebate for a married couple filing jointly was 5 percent of $\$ 12,000$, or $\$ 600$. The rebates for taxpayers with other marital status were calculated in the same manner.

The tax rebates were substantial, both from the point of view of an average household or in aggregate. The Treasury calculated that 92 million received a rebate check, with 72 million receiving the full amount. The rebates amounted to $\$ 38$ billion, or approximately 0.4 percent of 2001 GDP. Median family income in 2000 was about $\$ 41,000$, so a $\$ 600$ rebate represents about 1.5 percent of median annual income and a greater share of disposable income for a typical household. Because the size of the rebate was capped, as a fraction of income it declined as income rises once a family receives the maximum rebate.

The remainder of the paper is organized as follows. Section 2 presents our survey methodology and our findings about the spending rate from the tax rebate. Section 3 discusses some of the criticisms of and potential problems with surveys. We use results from the follow-up surveys to address the validity of survey responses. Section 4

\footnotetext{
${ }^{1}$ The description of the rebate program and the first survey draws on Shapiro and Slemrod (forthcoming).
} 
examines aggregate economic outcomes and how our survey results inform them. Section 5 offers our conclusions.

\section{Survey Evidence on the Spending Rate}

This paper reports on three surveys that concern spending of the tax rebate. Our first survey was conducted in August, September, and October 2001, which overlapped or shortly followed the mailing of rebate. Our second survey was conducted retrospectively in March and April of 2002. A subset of respondents responded to both surveys. The final survey--which asked about a hypothetical, temporary rebate--was conducted in midSeptember to mid-October of 2001. Table 1 summarizes the surveys.

\subsection{Survey Methodology}

Our first survey instrument was a rider on the University of Michigan Survey Research Center's Monthly Survey, also known as the Survey of Consumers. The Monthly Survey provides a representative sample of households in the contiguous $48 \mathrm{U}$.S. states and the District of Columbia. The survey's core content contains questions about expectations of economy-wide and family economic circumstances that are the basis of the University of Michigan Index of Consumer Sentiment.

The Survey of Consumers is a random digit dial survey of approximately 500 households. Each month, it includes about 300 new respondents and 200 respondents reinterviewed from six months earlier. We use this panel structure for our reinterview survey discussed below. ${ }^{2}$

The survey was conducted in August, September, and October 2001. The first two months of data were collected while households were in the midst of receiving rebate checks. By October, most households entitled to checks should have received them.

The tax rebate survey module begins by briefly summarizing the tax policy change and the rebate, and then addresses the household response to the rebate. Specifically, the key question was as follows:

\footnotetext{
${ }^{2}$ See http://www.sca.isr.umich.edu/ for more information about the Survey of Consumers.
} 
Earlier this year a Federal law was passed cutting income tax rates and expanding certain credits and deductions. The tax cuts will be phased in over the next ten years. This year many households will receive a tax rebate check in the mail. In most cases, the tax rebate will be $\$ 300$ for single individuals and $\$ 600$ for married couples. Thinking about your (family's) financial situation this year, will the tax rebate lead you mostly to increase spending, mostly to increase saving, or mostly to pay off debt?

\subsection{Results: First Survey}

Overall, only 21.8 percent of households reported that the tax rebate would lead them to mostly increase spending. Furthermore, there was no evidence that the spending rate was higher for low-income households, as might be expected if liquidity constraints are driving the cross-sectional variation. Shapiro and Slemrod (forthcoming) discuss the survey results in more detail. In that paper we draw three policy implications: (i) the tax rebate had a small impact on aggregate demand and therefore may not have succeeded in providing a short-run stimulus, (ii) there is no evidence that a tax rebate targeted at lowincome households would be more effective in stimulating aggregate demand, and (iii) the spending rate may be contingent on aggregate conditions that are difficult to anticipate.

\subsection{New Evidence from 2002 Retrospective and Post-9/11 Surveys}

To shed further light on these issues, we drafted two separate follow-up survey instruments. First, we designed a set of questions--including the principal question from the 2001 survey--as a module for the March and April 2002 Survey of Consumers. The total sample size was 1,002. For each month about 40 percent had also been surveyed six months earlier, and thus had been asked the earlier set of questions in September or October of 2001. In total, 405 of the 1002 surveyed in 2002 had also been surveyed in 2001. 
The retrospective question was as follows:

Last year a Federal law was passed cutting income tax rates and expanding certain credits and deductions. Some tax cuts took effect last year and others will be phased in over the next nine years. Last year many households received a tax rebate check in the mail. In most cases, the tax rebate was $\$ 300$ for single individuals and $\$ 600$ for married couples. Did the tax rebate lead you mostly to increase spending, mostly to increase saving, or mostly to pay off debt?

The third instrument was part of an extraordinary survey effort in the fall of 2001. In response to the attacks on New York and Washington, D.C. of September 11, the University of Michigan Survey Research Center fielded a new survey, called How America Responds (henceforth $H A R$ ). The principal aim of this survey was to study whether there were shifts in economic, social, political, and psychological attitudes following the attack. Most important for the question at hand, the survey included a hypothetical version of the question about tax rebates that was included in the August, September, and October 2001 Surveys of Consumers discussed above. It read as follows:

This year many households have received a tax rebate check in the mail amounting to $\$ 300$ or $\$ 600$. Suppose the Federal government cut taxes an additional $\$ 1000$ per household for this year only and sent this $\$ 1000$ rebate to you (your family) in October of this year. Thinking about your (family's) financial situation this year, would the tax rebate lead you mostly to increase spending, mostly to increase saving, or mostly to pay off debt?

The last sentence of the question is identical to the Survey of Consumers rebate question. However, the tax rebate about which it asks is hypothetical, amounts to $\$ 1000$ instead of $\$ 300$ or $\$ 600$, and is not part of a larger multi-year tax cut. 


\subsection{Spending Rates: Follow-up Surveys}

\subsubsection{Survey of Consumers Retrospective Survey}

The aggregate responses in the retrospective Survey of Consumers instrument were strikingly similar to the answers given in 2001. While in the 2001 survey, the weighted responses were 21.8 percent, 32.0 percent, and 46.3 percent, in 2002 they were 24.9 percent, 27.1 percent, and 48.0 percent for mostly spend, mostly save, and mostly pay down debt, respectively. Of those in the second wave who were also in the first wave, the weighted breakdown was 28.1 percent mostly increase spending, 25.2 percent mostly increase saving, and 46.7 percent mostly pay off debt. ${ }^{3}$ Given that there is a tendency to report higher spending rates conditional on having received the rebate [see Shapiro and Slemrod (forthcoming)] and that most individuals would have received the rebate by the time of the retrospective survey, the findings of the initial and retrospective survey are practically identical.

\subsubsection{Post-9/11 Survey}

The results of the HAR survey also corroborated the basic finding of a low spending rate. Overall only 16.6 percent said they would mostly spend the hypothetical $\$ 1000$ rebate, 36.5 percent said they would mostly increase saving, and 46.9 percent said they would mostly pay off debt. Given that the hypothetical rebate was temporary and not accompanied by any other income tax cuts, a lower reported spending rate in this context is consistent with economic theory. Nonetheless, the spend percentage is quite close to what we find for the actual rebate. Like our estimate for the actual tax rebate, the spending rate from the hypothetical rebate is much smaller than found in earlier studies.

In sum, the finding that slightly less than a quarter of consumers would mostly spend a tax rebate is not confined to the initial survey conducted in the late summer and early fall of 2001. It has been corroborated in a retrospective survey of many of the same

\footnotetext{
${ }^{3}$ This last calculation uses the weights of the second wave. Using the first-wave weights, the percentages are $28.9,26.1$, and 45.1, respectively. Recall that the second wave only surveyed those people who were surveyed in either September or October of 2001, and not those surveyed in August of 2001, in addition to many people who were not part of the first wave.
} 
households that participated in the original survey, and in a separate survey that asked a similar question regarding a hypothetical second round of tax rebates.

\section{Validating Surveys}

Given the important policy implications of these findings, it is worthwhile to be circumspect about the soundness of the methodology and to present evidence about the validity of the survey results. The next subsection addresses the issue of whether people mean what they say in such a survey. In subsequent subsections we try to address this question using our follow-up surveys. We consider the ability to explain cross-sectional variation in survey responses, the consistency of individual responses across waves of the survey, and new questions on the follow-up surveys designed to probe for ambiguities in how respondents interpret our question about spending or saving the rebate.

\subsection{Do People Mean What They Say?}

One possible caveat is that survey answers might not reflect households' actual behavior. In support of this criticism, Souleles (forthcoming) cites Robert Frost as follows: "Never ask of money spent/Where the spender thinks it went/Nobody was ever meant/To remember or invent/What he did with every cent." Of course, the use of this quotation by Souleles is quite ironic in view of the fact that his estimate of the marginal propensity to consume (MPC) out of the Reagan tax cut is based entirely on the Consumer Expenditure Survey, which asks people to remember expenditures over the previous three months on food, alcohol, utilities, household operations, house furnishings and small appliances, rent and other durable shelter expenses, apparel and services, transportation, entertainment, personal care, reading materials, tobacco, and miscellaneous expenses. Not every cent, but close. ${ }^{4}$

The point is that economic analysis based on surveys is standard, indeed ubiquitous, in economics. The real methodological issue and the difference between, for example, the Consumer Expenditure Survey and the question we added to the Survey of

\footnotetext{
${ }^{4}$ Souleles's research uses the Consumer Expenditure Survey's quarterly retrospective survey, as does virtually all similar research. Stephens (2001) is unique in this literature in using the Consumer Expenditure Survey's diary survey, where individuals keep track of their spending over a two-week period in a contemporaneously-completed diary.
} 
Consumers, is that we asked people about their consumption compared to a counterfactual state of the world in which they received no rebate. The issue is not whether the survey reflects actual behavior, but how accurately it measures actual behavior relative to a counterfactual.

Even if the survey question responses reflect systematic cognitive errors, one might learn from differences across time in the answers to similarly worded questions. For example, a similar but not identical question asked by Shapiro and Slemrod (1995) about the 1992 change in standard income tax withholding amounts revealed a 43 percent spend rate, compared to the 21.8 percent spend rate found in 2001. Souleles (forthcoming) reports on a New York Times/CBS News poll in May 1982 that found that 50 percent of respondents said they would spend the second phase of the Reagan tax cut; this compares to his estimate of 0.6 to 0.9 for an overall MPC for nondurable goods. Katona and Mueller (1968) conducted similar surveys after the 1964 tax cut. Three months after the change in withholding, about 50 percent of respondents said they spent the increased income on "general" or "everyday" expenses, 13 percent said they saved it, and about one-third were unable to say what they did with it. Thus, in the recent past, about half of people indicated that they would spend a tax cut delivered in one form or another, and in 2001 only about a quarter said this. The conclusion that the spending rate out of the 2001 tax rebates was lower than in similar past episodes is reinforced by the fact that, in a Gallup Poll released on July 24, 2001, only 17 percent of those surveyed said they would spend the tax rebate, while 32 percent said they would save or invest it and 47 percent said they would use it to pay off bills. Thus, a similar but distinct survey conducted at about the same time also indicates a very low spending rate out of the rebate.

\subsection{Can We Explain Cross-Sectional Variation?}

The fact that in Shapiro and Slemrod (forthcoming) we can find little that systematically explains the cross-sectional variation in the spending rate might suggest that the answers given are essentially random. There were, however, some systematic patterns. For example, those respondents age 65 and over were significantly more likely to spend. Table 2 shows the spending rates by age category in the first and second wave (discussed below). In both waves the spending rate is significantly higher for those of age 65 or 
over compared to everyone else. Shapiro and Slemrod (2001, Tables 10 and 11) suggest that the spending rate of the aged is significantly higher than the rate of others even when other respondent characteristics are held constant. This age pattern is entirely consistent with the life-cycle model. As another example, the spending rate is positively related to expected business conditions. As Table 3 shows, in the first wave those that expect the economy in a year to be good or good with qualifications had a spending rate of 26.2 percent, while those who expected the economy to be bad or bad with qualifications had a spending rate of 19.9 percent. For the second wave, the spending rates are 26.7 percent and 17.7 percent, respectively. Both differences are statistically significant. This difference is consistent with the behavior of forward-looking consumers presuming that the aggregate performance of the economy is relevant for individuals' prospects. Below we discuss some further attempts to understand the cross-sectional variation in spending rates.

With the retrospective survey results, we can further pursue explaining the crosssectional variation along two dimensions. First, we can investigate whether the retrospective answers can be better explained than the prospective or concurrent answers

were. Second, we can investigate the explanatory power of a few new questions added to the 2002 survey. In addition, we can examine the $H A R$ survey for further evidence.

\subsubsection{Explaining Retrospective Spending Rates}

As in the first wave, there is no indication that low-income households were more likely to mostly spend the rebate-in fact, higher-income households were more likely to say that the tax rebate led them to mostly increase spending. The positive relationship between income and spending rate is even more striking in the second-wave data. While the difference in spending rates between the lowest and highest income groups was 6.5 percent (24.1 percent versus 17.6 percent) in the first wave, it is 11.4 percent in the second wave (33.2 percent versus 21.8 percent). Using the second-wave data, it is still true that there is no significant relationship between the average spend/save decision and one's personal finances compared to a year ago. As in the first wave, those who say their financial condition is better than last year are more likely to spend. In the first wave, the percentages were 23.0, 25.6, and 16.6 depending on whether the respondent is better off 
now, about the same, or worse off now. In the second wave they are 26.7, 26.1, and 21.2. However, as in the first wave, there is no monotonic relationship between the spend/save decision and one's expected personal finance position next year compared to the current year.

There is a notable change in the spending rate when respondents are characterized by both their financial condition compared to last year and their expected financial condition next year compared to this year. In Shapiro and Slemrod (forthcoming, Table 3B), we detect no clear difference in average spending rates between those who were temporarily in good condition or temporarily in bad financial condition. For example, those who considered themselves in temporarily good times (i.e., they thought themselves to be better off than last year, but expected to be worse off in the next year) have a spend percentage of 22.0, hardly different than the overall average. In the second wave, however, the spend percentage of this group is 43.6 , much higher than the overall average.

We then restricted the sample to those respondents who gave valid answers in both waves of the survey, which reduced the sample to 344 observations. We then ran regressions in pairs. In the first of each pair the dependent variable was the answer given to the spending question in the first wave; in the second of the pair, the dependent variable was the (retrospective) answer given in the second wave. The independent variables are always the answers given in the first wave. One interesting pattern emerges from this exercise. The positive association with the spending rate of the feeling that tax cuts would improve either one's own situation or the economy holds only for the first wave. This could be caused by a reduced perceived salience of the tax cuts as an important economic factor by early 2002; in the late summer of 2001, the tax cuts (and rebates) were a major focus of attention, at least until September 11.

\subsubsection{New Questions to Assess Liquidity Constraints}

We added three new questions to the 2002 survey module in order to better understand why for some families the rebate led them to consume more, and for other families this did not happen. The hypothesis the three questions address is that, at the time of the rebates, some families had become overextended in the sense that their asset position was 
too low relative to their income expectations. According to this hypothesis, given the inertia of spending plans, these families would have been pleased to use the rebate to bolster their asset position. The first of the three questions asks "Has the amount of spending (you/your family) regularly spends increased considerably in the last two years?" To this question 37.0 percent of the respondents answered yes. Next, we asked, “(Do you/does your family) have enough income to sustain your current level of spending for the foreseeable future. To this question 79.1 percent said yes. According to our hypothesis, those who answer no to this question would be especially likely to not spend the rebate. Finally, we asked "If (you/your family) were to have a financial setback, such as losing a job or facing a large unexpected expense, how difficult would it be for (you/your family) to cut back on your usual spending? In response to this question, 21.1 percent said it would be very difficult, 30.4 percent said it would be somewhat difficult, 28.7 percent said it would be slightly difficult, and 19.8 percent said it would not be difficult. According to our story, those who find it difficult to cut back on their usual spending would be more likely to save the rebate rather than spend it.

Do the responses to these questions have a significant association with spend/save rates? Based on cross-tabs, the answer is mixed. Those who had experienced a significant increase in spending were slightly more likely to have mostly spent the rebate, 26.1 percent versus 24.2 percent; this is not a statistically significant difference. However, there is a clear and significant difference in spending rates between those who say that a spending increase is sustainable and those who say it is not sustainable. Of those who say it is sustainable, 26.7 percent mostly spent the rebate, while only 15.4 percent of those who say it is not sustainable mostly spent it; this difference is significant at the 99 percent confidence level. Finally, those who said it would be very difficult to cut back spending if there were a financial setback were significantly less likely to mostly spend the rebate than people who gave one of the other three answers, 19.2 percent versus 26.1 percent. There was, however, no significant difference in spending rates among those who answered that cutting back spending would be somewhat, slightly, or not difficult.

We have pursued the explanatory power of these variables by performing linear probability regressions. In each regression, we control for the log of income, dummy 
variables for stock ownership categories, marital status, and age categories. The answers to none of these three new questions have a statistically significant coefficient in explaining the spending rate. Thus, although the cross-tabs suggest some support for our hypothesis, the regression analysis does not.

\subsubsection{Further Evidence from the Post 9/11 Survey}

There is also no indication in the HAR survey that low-income people were more likely to mostly spend the rebate. In cross-tabulations, there is no significant relationship between spending rates and personal finances compared to a year ago or to personal finances expected next year compared to this year. However, a linear probability analysis that holds income, wealth categories, age categories, and marital status constant does indicate that being in better financial condition than a year ago is associated with a higher spending rate.

As in the Survey of Consumers, one answer that is significantly associated with spending rate is the respondent's assessment of the state of the national economy one year in the future. For those who say it will be good or good with qualifications, the spending rate is 25.9 percent. For those who say it will be bad or bad with qualifications, the average spending rate is 12.4 percent. (It is 16.4 percent for those who say it will be neutral.) This estimated 13.5 percent difference is much larger than in the Survey of Consumers, and survives the inclusion of other variables in a multiple regression framework. Thus, in terms of the ability to explain the cross-sectional differences in spending rates, a person's expectations of where the aggregate economy is headed seems to be much more powerful than their expectations about their own family's financial conditions.

\subsection{Consistency of Answers across Waves}

The previous section documented that the two waves of the Survey of Consumers gave similar aggregate spending rates. A stronger check on the validity of the survey answers is to compare the answers given by the same people to the concurrent survey in 2001 and the retrospective survey in 2002. Table 4 shows the cross-tabulation of answers across the two surveys, while Table 5 shows the results of combining the "mostly increase 
saving" answers with the "mostly pay off debt" answers into a "don't spend" composite. If the correlation across waves was perfect, the diagonal elements of these tables, shown in bold, would contain all of the observations. In fact, the correlation is substantial, but not perfect. Of those who in 2001 said that the tax rebate led them to mostly spend the rebate, 61.8 percent repeated that answer in 2002. Of those that in 2001 said that it led them to mostly not spend it, 81.7 percent repeated that answer in 2002. The (first-wave) weighted correlation is 0.415 , which is significant with 99 percent confidence. If we repeat the same calculation for only those 245 households who when surveyed in 2001 had already received the rebate, the correlation rises to 0.439 .

We would expect that responses to our question could be quite noisy. In addition to response noise due to the unfamiliarity of the question, the use of the term "mostly" could result in a given respondent changing his or her response due to a small change in their assessment of the underlying spending propensity. Thus, given the nature of the survey and its subject matter, there is a fairly high level of consistency of responses across waves.

\subsection{Respondents' Horizon}

If those respondents who report that the rebate led them to mostly save the rebate or mostly pay down debt plan to use the extra saving or reduced debt to finance consumption in the near future, our findings would have very different implications than if the saving or debt repayment were more lasting. Two of the questions in the second wave of the Survey of Consumers directly addressed the question of whether an intention to save the rebate, for example, meant to save it for a purchase a few weeks or months later, or rather to add to one's assets over a longer period of time. In particular, those who answered that the rebate led them to mostly save were asked "Will you use the additional savings to make a purchase later this year, or will you try to keep up your higher savings for at least a year?" The response was overwhelmingly the latter, with 85.3 percent choosing that answer. A similar question was asked to those who said they would mostly use the rebate to pay down debt: "Will you use the lower debt to make a purchase later on this year, or will you try to keep your lower debt for at least a year?" In this case as well, those surveyed overwhelmingly chose the latter answer, 93.4 percent to 
be exact. Thus, the new survey evidence strongly suggests that the people who reported mostly not spending the tax rebate largely intended the resulting increase in assets (or decrease in debt) to last at least a year.

\section{The Tax Rebates and the Aggregate Economy}

\subsection{Tax Policy Changes and Aggregate Time Series Data}

Aggregate time series analysis of tax policy changes is difficult because tax policy changes are rare events and because they are potentially confounded by other events. Indeed, both the 2001 recession and the September 11, 2001 terrorist attacks are substantial confounds to studying the 2001 policy changes in time series. Such potential confounds were one of the reasons that led us to pursue the survey approach to studying the policy change. Nonetheless, in this section we do examine the aggregate data to see what they might reveal about the effect of the tax policy, and to what extent it is consistent with the survey results.

Table 6 shows the magnitude of the size of the rebates and the change in withholding as a result of the 2001 tax bill from official, static revenue estimates. The rebate payments were spread mainly over July, August, and September, with a peak in August. There was a more modest reduction in withholding during the second half of 2001 as a result of the 0.5 percentage point reduction in tax rates for the old 28 percent and higher brackets that was implemented as a 1 percentage point reduction in withholding, effective in July of 2001. The 2002 tax cuts were larger than those in 2001, but accrued evenly throughout the year. In 2002, the amount corresponding to the rebate was implemented as lower withholding for the new, 10 percent bracket; the rate reduction of 1 percentage point for the upper brackets applied throughout the year.

The rebates in July, August, and September 2001 were sizeable relative to aggregate tax payments and aggregate disposable income. For the first two quarters of 2001, National Income and Product Accounts personal tax and non-tax payments averaged $\$ 1,338.3$ billion at an annual rate. During the third quarter, they averaged $\$ 1,181.9$ billion, a reduction of 12 percent. The rebates were 1.1 percent of disposable income in July, 2.8 percent in August, and 1.7 percent in September. 
Our survey results suggest that most households mostly saved the rebates. How does that conclusion accord with the aggregate data? Figure 1 shows monthly personal saving as a percent of disposable personal income. For the first six months of 2001, the savings rate averaged around 2 percent. Figure 1B shows that this low savings rate was the culmination of a decline in the savings rate that began in the $1980 \mathrm{~s}$, but accelerated in the middle of the 1990s. Figure 1A shows a spike in the saving rate precisely at the same time the tax rebates were mailed in July, August, and September 2001. This spike in saving is consistent with the finding of our survey that most households mainly saved the rebate. 5

Is the spike in saving due to the rebate? Beginning in July 2001, Figure 1A decomposes the total personal saving rate into two parts. The lightly shaded area is the reduction in personal tax payments owing to the change in policy, i.e., the amounts shown in Table 6 as a percent of disposable income. The total height of the bars in Figure 1A is the official personal saving rate, so that the dark area is simply the saving rate excluding the policy-induced changes in tax payments. The pattern of Figure 1A is consistent with a finding that in July and August of 2001, a sizeable fraction of the tax rebates went straight into saving. The spike in the saving rate, which is very noticeable even in Figure 2A over the longer time series, is fully accounted for by the decrease in tax payments. Excluding the tax changes, the saving rate in July and August would have been very similar to the rate in the first half of the year, all other things equal.

The situation becomes much more complex beginning in September 2001. The saving rate remains high. The high rate relative to the first half of the year is partially accounted for by the decrease in tax payments, but the dark-shaded residual also shows an increase. This blip downward in consumption relative to income likely is due to a reduction in spending while the nation's attention was riveted on the terrorist attack. October saw a recovery in spending in all categories of consumption, but especially for

\footnotetext{
${ }^{5}$ The personal saving rate has come under criticism recently as a measure of saving, e.g., because it excludes capital gains. See Gale and Sabelhaus (1999). Though this criticism of the saving rate may be important in some contexts, here it is a convenient indictor of how the flow of spending moved contemporaneously with the flow of income. We also consider below measures of aggregate consumption expenditure.
} 
automobiles in response to the zero-percent financing incentives offered by automotive companies.

Figure 2 charts total personal consumption expenditures and its major components in chain-weighted 1996 dollars. The shaded areas show July, August, and September 2002 when the rebate was mailed. Several facts emerge from these charts.

- $\quad$ Consumption growth discernibly slowed by late 2000 from its robust rate of the late 1990s. This slowdown apparently antedates the NBER reference peak of March 2001.

- There is no discernable movement upward in consumption during the period of the rebate.

- $\quad$ The 9/11 spike downward in spending and the spike upwards in October is clearly evident.

Hence, consumption expenditures tell the same story as the saving rate.

It is possible that the decline in saving in the fourth quarter of 2001 to some degree reflects the smoothing of spending from the rebates over the second half of the year. This seems unlikely, however, on two counts. First, the post-9/11 incentives to purchase automobiles are a more direct explanation of the decline in saving in the fourth quarter. Second, the decline ended abruptly in 2002, with the saving rate appearing to be higher than its pre-rebate level. Hence, the 2002 saving rate does not suggest deferred spending from 2001.

All in all, especially for July and August of 2001 prior to the confounding event of 9/11, Figure 1 supports the proposition that virtually all of the tax cuts went into personal saving. This mechanical calculation is consistent with the implication of the survey that most of the rebate was saved. To be sure, care needs to be exercised in interpreting the finding in terms of an economic model. For example, consumption smoothing would mandate a spike in saving upon receipt of the rebate. Yet, the aggregate data appear to be telling a very similar story to that of the survey.

\subsection{Previous Episodes}

The Tax Reduction Act of 1975 provided for a temporary 10 percent rebate of 1974 taxes up to a maximum of $\$ 200$. It was mailed from late April to mid-June of 1975. Blinder 
(1981) finds that each rebate dollar raised consumption by about 16 cents in the quarter it was received and that it had larger effects in later quarters. Modigliani and Steindel (1977) find much smaller effects. Poterba (1988) finds that consumption of nondurables increased by between 18 and 24 percent of the rebate in the month received, but finds that the change in service consumption was negligible. Hence, these studies of the 1975 rebate generally find modest spending from the rebate. Of course, the 1975 rebate corresponded to a temporary tax cut, which the standard theory suggests should be saved.

Note that Figure 1B indeed shows a dramatic spike up in saving contemporaneously with the receipt of the 1975 rebates. This corresponds to a temporary drop in tax receipts; the increase in disposable income did not have a corresponding increase in consumption, so the saving rate spiked. [See Survey of Current Business (June 1975, p. 1).] The other big spikes in the saving rate since 1975 shown in Figure 1B can also be associated with tax changes. In April 1987, there is a spike down in the saving rate. This corresponds to the decrease in disposable income associated with final settlements of 1986 tax liabilities. The 1986 tax bill led to acceleration of capital gains realizations that increased final settlements. There were also changes in withholding (decreases in 1987:1 and increases in 1987:2) as individuals adjusted withholding to the new, lower rates. [See Survey of Current Business (July 1987, p. 6).]

There are also more modest, though still noticeable, spikes up in the saving rate in December of 1992 and December of 1993. These occurred because individuals and firms moved the payment of income forward in time (e.g., via Wall Street bonuses) owing to the anticipation of tax increases. In 1992, the election of President Clinton and statements by incoming members of his administration led to an expectation of tax increases. The Omnibus Budget and Reconciliation Act of 1993 increased marginal tax rates. It also increased the base for Hospital Insurance (HI) payroll taxes beginning in tax year 1994 by making HI covered earnings subject to the combined employer/employee tax rate of 2.9 percent, thus giving an incentive to taxpayers to shift earnings from 1994 to $1993 .{ }^{6,7}$

\footnotetext{
${ }^{6}$ See Economic Report of the President 1994 (pp. 73-74) and Parcell (1999) for more details.

${ }^{7}$ This income shifting is captured in official statistics. To put the National Income Accounts on an accrual basis, the BEA routinely estimates wage accruals less
} 
Other factors, of course, contribute to swings in the saving rate. For example, swings in farm income are substantial in 1987 and 1993 [See Survey of Current Business (July 1987, p. 5; January 1994, p. 5)]. Nonetheless, swings in disposable income associated with tax changes do coincide with the biggest spikes in the saving rate in Figure 1B. Hence, in 1975, 1987, 1992, 1993, and 2001, there are spikes in saving that are consistent with individuals smoothing consumption over temporary changes in disposable income arising from tax changes, or changing the timing of income so that tax liabilities are minimized.

\subsection{Converting Survey Responses into an Aggregate MPC}

The aggregate marginal propensity to consume (MPC) from the rebate is an important input into studying the aggregate impact of the tax rebate. Our survey does not provide

this directly. Instead, it offers self-reported estimates of the fraction of people who would either mostly spend the rebate or mostly save it, either by adding it to assets or repaying debt. We could have inquired about the MPC directly on the survey by asking "What fraction of the rebate did you spend?" In designing our survey instrument concerning the 1992 rebate, we decided that asking about a fraction was too complicated. ${ }^{8}$ We used the same design decision for the survey instruments concerning the 2001 rebate.

With some assumptions about what range of individual MPC's corresponds to "mostly" spending or mostly saving and the distribution of those individual MPC's, our aggregate answers can be converted to an aggregate MPC. Under extreme assumptions, the correspondence need not be close, and could even be misleading. For example, if "mostly spend" corresponds to an MPC of 0.51 and "mostly not spend" corresponds to an

disbursements (WALD) to distinguish between the timing of payments and when the payments are earned. From 1959 to 1991, the maximum WALD in any quarter was 2.5 billion dollars at a seasonally adjusted annual rate. In over half of the quarters over this period, the WALD was zero. In contrast, the WALD in 1992:4 was -63.0 billion dollars, which was largely offset in 1993:1 by a value of 72.1 billion dollars. Similarly, in 1993:4, the WALD was -50.2 billion dollars and in 1994:1 it was 56.4 billion dollars. The saving rate shown in Figure 1 (as well as in BEA releases) is on a disbursement basis; the increased disbursements match the spike in saving at the ends of 1992 and 1993. 
MPC of 0.49 , then the aggregate MPC is close to 0.50 regardless of what our survey reveals. The survey is thus uninformative. Seidman and Lewis (2002) consider another extreme case, in which all households have an MPC of 0.40 , which is therefore equal to the aggregate MPC, but our survey concludes that no one intends to mostly spend the rebate. In this case, our survey would be misleading; of course, this does not characterize the survey results.

More generally, it is reasonable to expect that there is a distribution of individual marginal propensities to consume between zero and one that is neither bunched right around 0.50 nor entirely at values of either zero or one. By making some plausible assumptions about the shape of this distribution, we can get a feel for the range of average, or aggregate, MPC's that is consistent with what the survey reveals. Consider, for example, if the probability density of individual propensities to consume is highest at a value equal to the fraction of people who mostly spend, and falls off linearly on both sides of this value. In the appendix we show that, with these assumptions, only values of the average MPC between 0.340 to 0.372 are consistent with one-quarter of the population having an MPC of 0.50 or less. Note that the aggregate MPC in this example is always greater than the fraction of people who mostly spend the rebate, but lies within a fairly small range.

\subsection{Bush Administration Estimates of the Aggregate Impact of the Tax Changes}

Did the tax rebate policy cause output to be higher in the second half of 2001 than it would have otherwise been? Although an analysis of this question is well beyond the scope of this research, our finding that most households mostly saved the rebate is potentially important for such an analysis. A Keynesian analysis would imply little aggregative stimulus if little of the rebate was spent. Similarly, because households perceived little change in wealth or government spending from the change in tax policy, ${ }^{9}$ it is hard to see how a classical analysis of the policy change would imply much short-run effect on aggregate outcomes. That is, a policy that moves assets from the government's

\footnotetext{
${ }^{8}$ Moreover, given the tendency of survey respondents to "heap" on round numbers, e.g., zero, 50-50, and 100 percent, it is not clear that asking about fractions would have given less lumpy and more informative data.

${ }^{9}$ See Shapiro and Slemrod (forthcoming) for this finding.
} 
balance sheet to private balance sheets with little perceived change in household wellbeing would be hard-pressed to generate aggregative effects in the framework of a classical model. Hence, the results of our survey do suggest that the 2001 change in tax policy was not highly stimulative to aggregate output.

The Bush Administration claimed, however, that the tax bill did provide a substantial short-run stimulus to the economy. According to a Council of Economic Advisers (CEA) white paper,

The tax relief also has provided valuable stimulus to economic activity in the short run. The quick enactment last year of the President's tax relief plan softened the recessionary headwinds in 2001 and has helped to put the economy on the road to recovery in 2002 (Council of Economic Advisers, 2002).

Specifically, the CEA estimates that the provisions of the tax bill added 1.2 percentage points (at an annual rate) to GDP during the last two quarters of 2001 and 0.5 percentage points to GDP during 2002. The CEA estimates were based on the total impact of the tax policy of $\$ 57$ billion in 2001 and $\$ 69$ billion in $2002 .{ }^{10}$ The majority of these amounts are the rebate in 2001 or the impact of new 10 percent bracket in 2002. Given that GDP in 2001 was about $\$ 10$ trillion, the CEA estimates imply that tax policy left GDP about $\$ 60$ billion higher by the end of 2001 and $\$ 112$ billion higher by the end of 2002 than it would have been without the tax cut. Mechanically, these numbers imply that the tax cut raised GDP roughly dollar for dollar in the second half of 2001, and with a multiplier substantially above one in 2002 .

The CEA provided us with the main details for its calculation. ${ }^{11}$ The procedure was as follows. The rebate was assumed to be half temporary (corresponding to the retroactive benefit of the 10 percent bracket from January to mid-year) and half

\footnotetext{
${ }^{10}$ These figures include initial reductions in the marriage penalty and changes in child credits not included in Table 6. (Also, there is a $\$ 1.1$ billion inconsistency in the change in withholding in 2001 between Table 6 and the estimate in the Budget, on which the CEA estimate is based.)
} 
permanent (corresponding to the permanent benefit of the 10 percent rebate from midyear and into the future). Changes in withholding and other changes were assumed to be permanent. These changes in income were analyzed via the Macroeconomic Advisers model. According to CEA staff, the model has an effective marginal propensity to consume (MPC) from permanent tax changes of about 0.5 , an effective MPC from temporary changes of about 0.15 , and a multiplier of about 2 . The simulation assumed that Federal Reserve interest rate policy was unaffected by the tax policy change.

Based on this description of how the policy was analyzed, it is straightforward to understand how the Administration arrived at estimates of the impact of the tax policy. How credible are these estimates? The results of this paper can shed light on this question only in regard to the spending of the rebate. The CEA assumed that about a third of it was spent, that is, half was subject to the MPC for permanent income changes of 0.5 and half was subject to the MPC for temporary changes of 0.15 . As discussed above, our survey finding that about one-quarter of households reported mostly spending the rebate could well be consistent with an aggregate MPC of one-third. ${ }^{12}$

Although arrived at via a different route than our survey's results, the CEA's assumption about the spending of the rebate is thus consistent with our survey finding. The CEA's finding that the tax changes were substantially stimulative rests on applying a large multiplier to a relative modest impetus to spending. The assumption that the Federal Reserve held interest rates constant also contributed to the finding of substantial stimulus. An alternative and perhaps more plausible assumption is that the Federal Reserve cut interest rates less in 2001 than it otherwise would have because, in setting its targets, it took into account the effect of the tax cut on aggregate demand. For example, if the Fed has a target path for nominal GDP, it will attempt to offset changes in fiscal policy by adjustments in monetary policy. Under this scenario, even a Keynesian

${ }^{11}$ This account of the CEA methodology is based on telephone conversations with two CEA senior economists on February 20, 2002.

${ }^{12}$ The CEA assumed that withholding changes were permanent. Given that they did correspond to changes in tax rates that would be in place under current legislation, this assumption is reasonable on its face. Our survey results do suggest, however, that many households did not perceive the tax bill to provide a permanent benefit, so this would argue for a lower MPC. On the other hand, according to the CEA, the macroeconomic 
analysis would suggest that the tax cuts would not increase GDP, but instead change the fiscal/monetary mix in the short run.

The Administration did not initially highlight short-run economic stimulus as a main objective of the tax policy. Indeed, congressional Democrats introduced the rebate policy, partly as a stimulus measure. It is not surprising, especially in light of the economic slowdown in 2001, that the Administration would claim that the tax cut gave the economy a boost.

It is interesting to know that the Bush administration bases its policy analysis on neoKeynesian macroeconomic models with substantial multipliers. This may come as a surprise to some of the Administration's supporters. Yet, the use of neo-Keynesian macroeconomic models for policy analysis is common practice at the CEA and is consistent with how analysis has been carried out in previous administrations.

\section{Conclusion}

The tax rebates sent out in the summer and early autumn of 2001 were a small part of the 10 -year tax cut bill that became law earlier that year. Although not originally part of the tax cut plan, as an economic slowdown became more apparent, one part of the tax cut for 2001 was converted into more visible checks sent out to taxpayer rather than reductions in withholding. One might speculate that incumbent politicians also guessed that household-voters would be more likely to recall their largesse if the tax cut took the form of a check as opposed to, for example, a reduction in tax withholding.

Did they work as a counter-recession policy? The answer to that question depends in part on households' propensity to consume out of the increased disposable income due to the rebates. Our survey-based research suggests that the spending rate was quite low compared to what many economists had expected. This finding appears in a contemporaneous survey and a retrospective survey that addressed the actual rebate plan. It also appears in answers to what would be the response to a hypothetical survey conducted soon after September 11. An examination of the NIPA data is completely consistent with a small impact on consumption. Yet, because it is impossible to know

model assigns an MPC from permanent income changes of one-half, well below the value of one mandated by the standard theory. 
what consumption would have been absent the rebates, aggregative analysis cannot be definitive. Nonetheless, that the counterfactual in aggregate data gives a similar result to the counterfactual that we pose to survey respondents is significant validation of the survey methodology. 


\section{Appendix}

Let $s$ be the fraction of people who are spenders, defined as people for whom the marginal propensity to spend, call it $m$, is greater than or equal to 0.50 . Assume that the probability density of $m$ looks like Figure A-1. In particular, assume there is a nonnegative probability density equal to $a$ of having $m=0$, and that the probability density increases linearly until it reaches a peak of $b$ at $m=d$, after which it decreases linearly until it reaches zero at $m=c$. (Note that $a, b, c$, and $d$ are not independent, because $\int_{0}^{1} f(m) d m=1$.) With these assumptions, we can calculate the relationship between the aggregate marginal propensity to consume, $\bar{m}=\int_{0}^{1} m f(m) d m$, and the parameters $a, b, c$, and $d$, for a given value of the average spending rate, $s=\int_{0.5}^{1} f(m) d m$. Note that this exercise also assumes that all individuals have equal income or, more specifically, equal weight in calculating the aggregate marginal propensity to consume.

Table A-1 shows the results of some calculations of $\bar{m}$ for various combinations of $a$, $b$, and $c$ with the further assumption that the modal $m$ is equal to the approximate value of the fraction of people who mostly spend, so that $d=S=0.25 .^{13}$ (Note that, given these assumptions, $c$ can equal 1 only in the case where the density function has a constant negative slope, so that the maximal density occurs at the minimum value of $m=0$, in which case $\bar{m}$ is 0.333 .) According to these calculations, the aggregate MPC, or $\bar{m}$, falls within a fairly tight range from 0.341 to 0.372 . It is, though, always greater than the assumed value of $s$, the fraction of people who mostly spend the rebate.

\footnotetext{
${ }^{13}$ Allowing $d$ to vary between 0.15 and 0.35 does not have a large effect on $\bar{m}$.
} 


\section{References}

Blinder, Alan S. 1981. "Temporary Income Taxes and Consumer Spending." Journal of Political Economy. 89: 26-53.

Council of Economic Advisers. 2002. President Bush's 2001 Tax Relief Softens the Recession. February 14.

Gale, William and John Sabelhaus. 1999. "Perspectives on the Household Saving Rate," Brookings Papers on Economic Activity, 1999:1.

Katona, George and Eva Mueller. 1968. Consumer Response to Income Increases. Brookings Institution: Washington, D.C.

Modigliani, Franco and Charles Steindel. 1977. "Is a Tax Rebate an Effective Tool for Stabilization Policy?" Brookings Papers on Economic Activity: 175-209.

Parcell, Ann. 1999. "Challenges and Uncertainties in Forecasting Federal Individual Income Tax Receipts.” National Tax Journal 52: 325-38.

Poterba, James. 1988. "The Reaction of Household Consumption to Predictable Changes in Social Security Taxes." American Economic Review 89: 959-73.

Seidman, Laurence S. and Kenneth A. Lewis. 2002. "Automatic Fiscal Policy: A New Design." Mimeo. Department of Economics. University of Delaware. July.

Shapiro, Matthew D. and Joel Slemrod. 1995. "Consumer Response to the Timing of Income: Evidence from a Change in Tax Withholding." American Economic Review 85: 274-83.

Shapiro, Matthew D. and Joel Slemrod. 2001. "Consumer Response to Tax Rebates." NBER Working Paper 8672. December.

Shapiro, Matthew D. and Joel Slemrod. Forthcoming. "Consumer Response to Tax Rebates." American Economic Review.

Stephens, Melvin, Jr. forthcoming.“'3rd of tha Month': Do Social Security Recipients Smooth Consumption Between Checks?" American Economic Review.

Souleles, Nicholas S. Forthcoming. "Consumer Response to the Reagan Tax Cuts." Journal of Public Economics. 
Table 1. The Surveys

\begin{tabular}{|c|c|c|c|c|}
\hline Survey & Dates & $\begin{array}{l}\text { Observations } \\
\text { (number) }\end{array}$ & Rebate question & $\begin{array}{l}\text { Spending rate } \\
\text { (percent) }\end{array}$ \\
\hline Survey of Consumers, Wave I & $\begin{array}{l}\text { August, September, October } \\
2001\end{array}$ & 1506 & Actual 2001 rebate & 21.8 \\
\hline Survey of Consumers, Wave II & March, April 2002 & $\begin{array}{l}1002 \\
405 \text { reinterview } \\
597 \text { new respondents }\end{array}$ & $\begin{array}{l}\text { Actual } 2001 \text { rebate, } \\
\text { retrospective }\end{array}$ & 24.9 \\
\hline How American Responds & $\begin{array}{l}\text { Mid-September to mid- } \\
\text { October, } 2001\end{array}$ & 752 & $\begin{array}{l}\text { Hypothetical } \\
\text { temporary rebate }\end{array}$ & 16.6 \\
\hline
\end{tabular}

Note: Number of respondents is unweighted. Spending rate is weighted fraction of responds receiving rebate who said they would spend it. 
Table 2. Spending Rates by Age Category

\begin{tabular}{ccc} 
& (percent) & \\
\hline Age Group & First Wave & Second Wave \\
\hline 29 or less & 13.7 & 18.7 \\
$30-39$ & 20.8 & 25.3 \\
$40-49$ & 24.8 & 23.2 \\
$50-64$ & 20.2 & 22.7 \\
Age 64 or less & 20.6 & 22.9 \\
Age 65 or over & 28.8 & 35.7 \\
\hline
\end{tabular}

Note: Entries in the table are the weighted fraction of households receiving the rebate who reported they would mostly spend the rebate. 
Table 3. Spending Rates by Expected Business Conditions Over the Next Year (percent)

\begin{tabular}{lcc}
\hline Expected Business Conditions & First Wave & Second Wave \\
\hline Good or good with qualifications & 26.2 & 26.7 \\
Neutral & 11.8 & 34.0 \\
Bad or bad with qualifications & 19.9 & 17.7 \\
\hline
\end{tabular}

Note: See note to Table 2. Few households are "neutral." 
Table 4. Relationship of Answers in First and Second Waves, All Responses (number of observations)

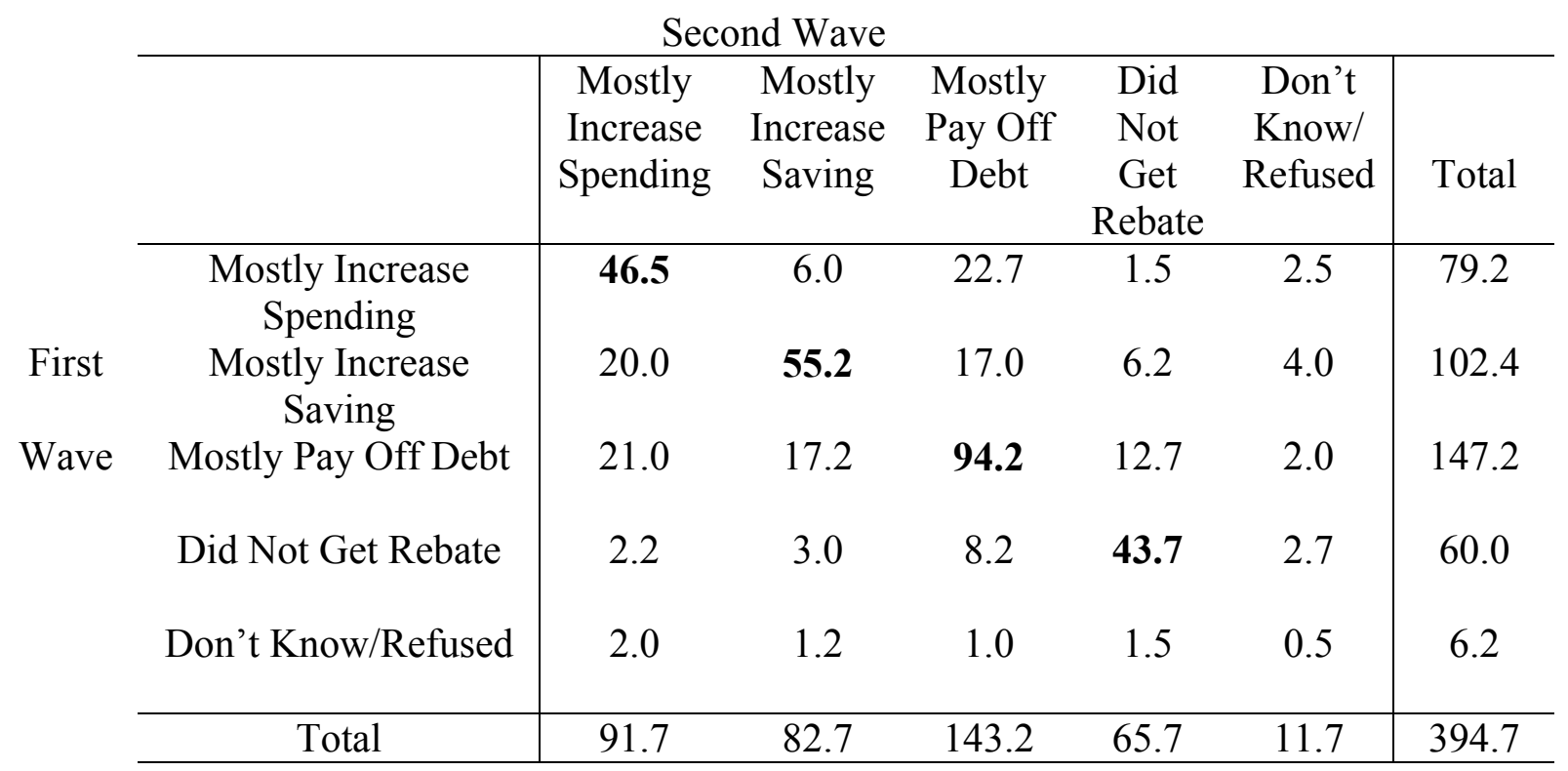

Note: Entries in the table are the (first-wave) weighted number of respondents. 
Table 5. Relationship of Answers in First and Second Waves, Spend versus Not Spend (number of observations)

\begin{tabular}{cc|cc|c} 
& \multicolumn{4}{c}{ Second Wave } \\
\cline { 2 - 4 } & & $\begin{array}{c}\text { Mostly } \\
\text { Spend }\end{array}$ & $\begin{array}{c}\text { Mostly Not } \\
\text { Spend }\end{array}$ & Total \\
First & Mostly Spend & $\mathbf{4 6 . 5}$ & 28.7 & 75.2 \\
Wave & & & \\
& & 41.0 & $\mathbf{1 8 3 . 6}$ & 224.6 \\
& Mostly Not Spend & & & 299.8 \\
\hline
\end{tabular}

Note: See Table 4. 
Table 6. Aggregate Change in Tax Payments.

Billions of Dollars, Annual Rate

\begin{tabular}{llccc}
\hline & Rebate & Withholding & Total \\
\hline 2001 & July & 81.4 & 13.7 & 95.1 \\
& August & 209.4 & 13.7 & 223.1 \\
& September & 131.2 & 13.7 & 144.9 \\
& October & 2.5 & 13.7 & 16.2 \\
& November & 5.0 & 13.7 & 18.7 \\
& December & 2.5 & 13.7 & 16.2 \\
& & & & \\
2001 & Calendar year & 36.0 & 6.9 & 42.9 \\
2002 & Calendar year & 0.0 & 52.0 & 52.0 \\
\hline
\end{tabular}

Note: Table shows changes in tax payments owing to changes in the 2001 tax bill. Figures are annual rate, i.e., the 2001 calendar year figure is half the average of the July through December. Sources: For 2001, BEA Personal Income releases. For 2002, Budget of the United States (January 2002). 
Table A-1. Implied Values of the Aggregate Marginal Propensity to Consume $(\bar{m})$ for Alternative Distributions of the Individual Marginal Propensities to Consume $(\mathrm{m})$

\begin{tabular}{cccc}
\hline$a$ & $b$ & $c$ & $\bar{m}$ \\
\hline 1.643 & 1.643 & 0.967 & 0.340 \\
1.558 & 1.678 & 0.960 & 0.341 \\
1.300 & 1.782 & 0.940 & 0.346 \\
1.011 & 1.899 & 0.920 & 0.351 \\
0.688 & 2.031 & 0.900 & 0.358 \\
0.321 & 2.181 & 0.880 & 0.365 \\
0.000 & 2.314 & 0.864 & 0.372
\end{tabular}

Source: See discussion in text and appendix. The distribution of $m$ is parameterized as in appendix Figure A-1. 
Figure 1. Personal Saving Rate
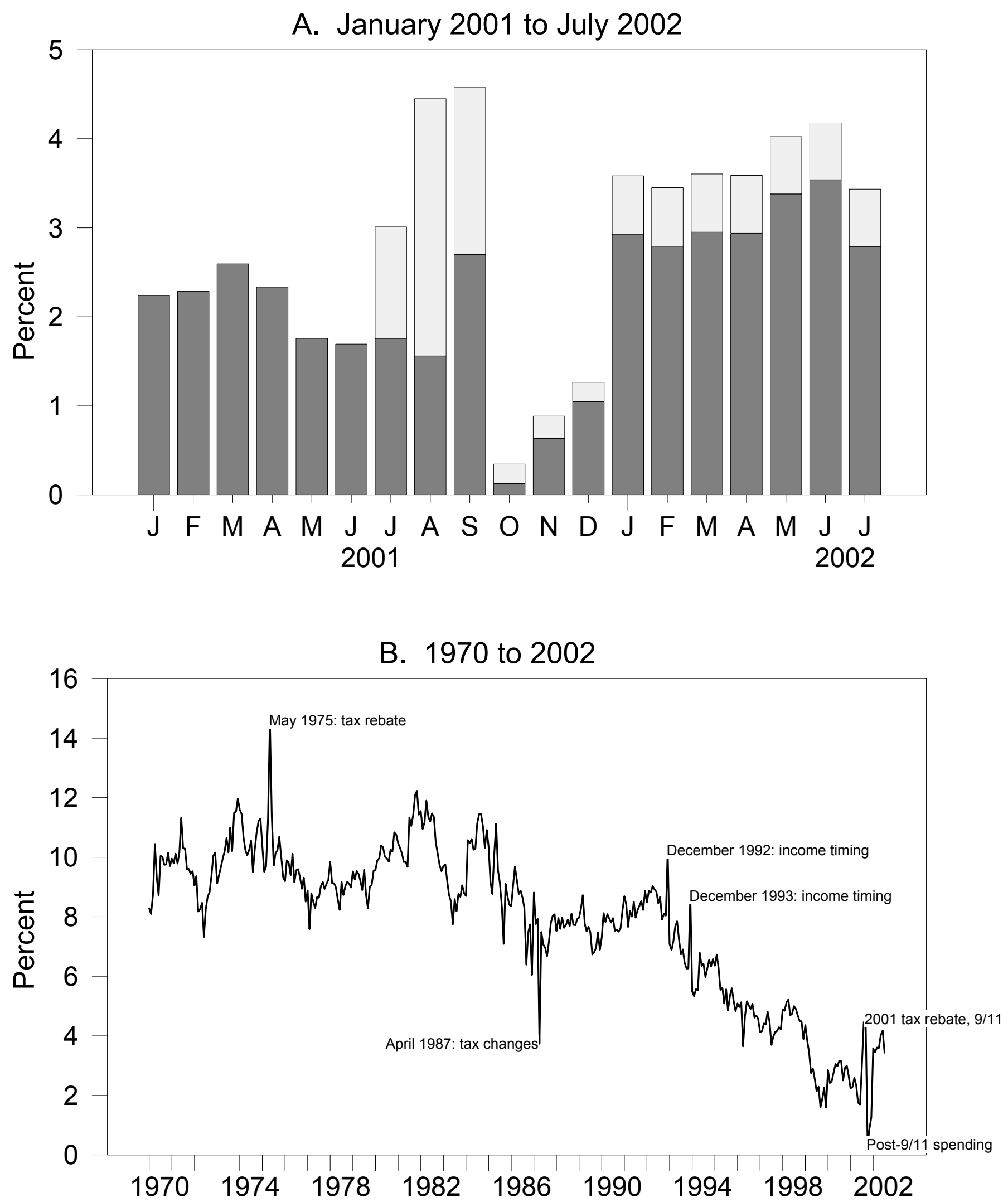

Note: Lightly shaded area in panel A is portion of saving accounted for by tax changes. 
Figure 2. Personal Consumption Expenditure
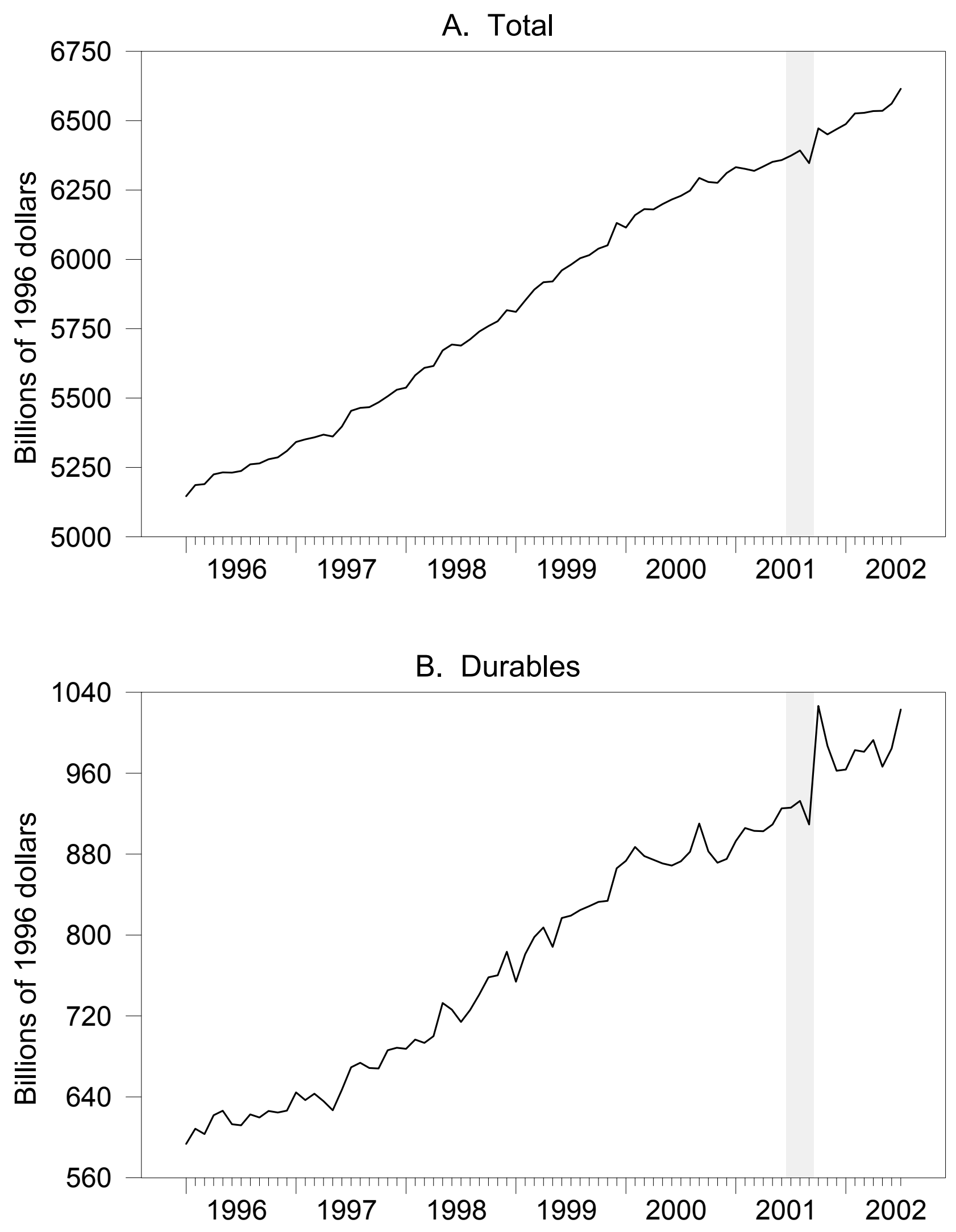

Note: Shaded area is July through September 2001 when rebates were mailed. 
Figure 2. Personal Consumption Expenditure (continued)
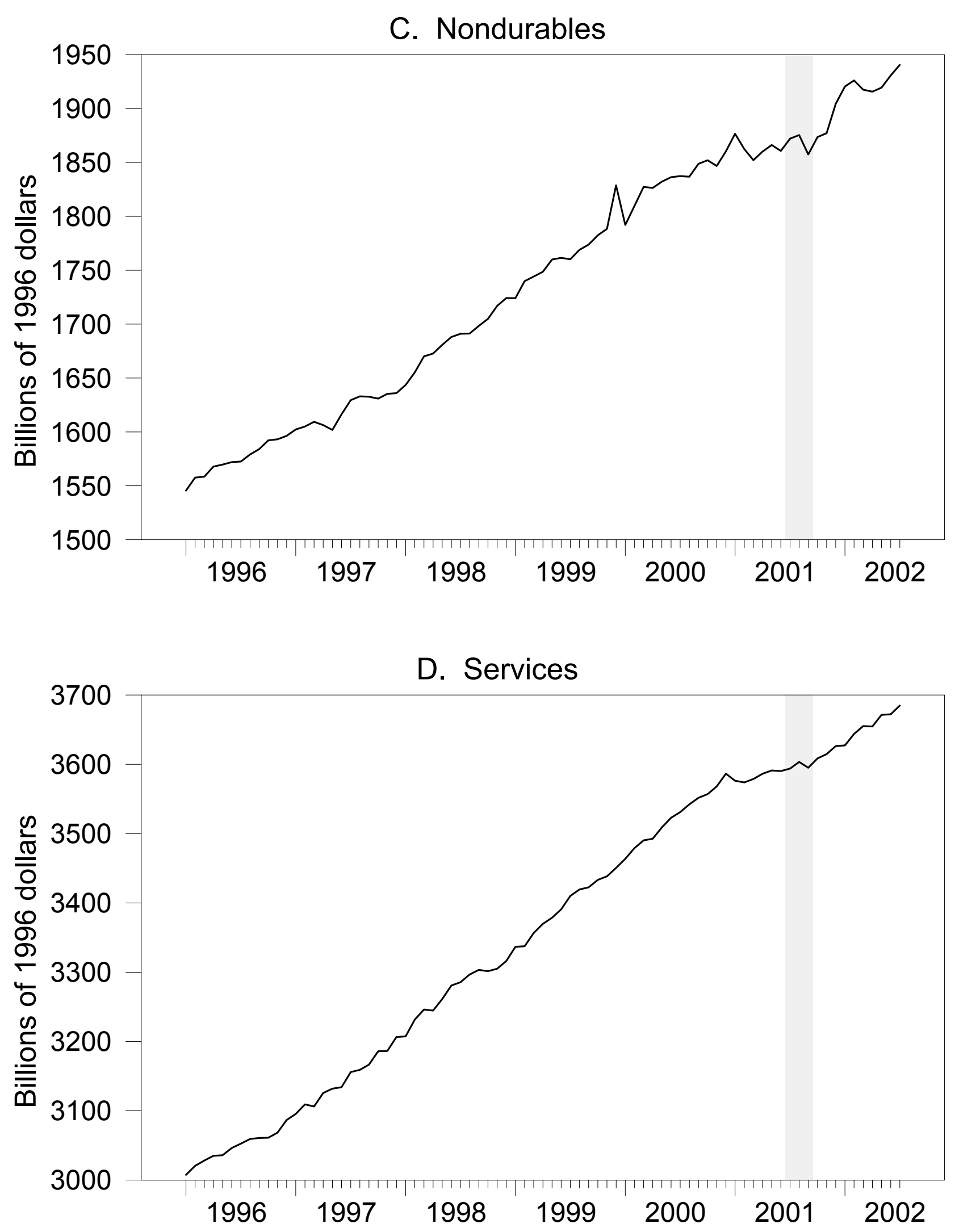

Note: Shaded area is July through September 2001 when rebates were mailed. 
Figure A-1

Illustrative Distribution of Individual Marginal

Propensities to Consume

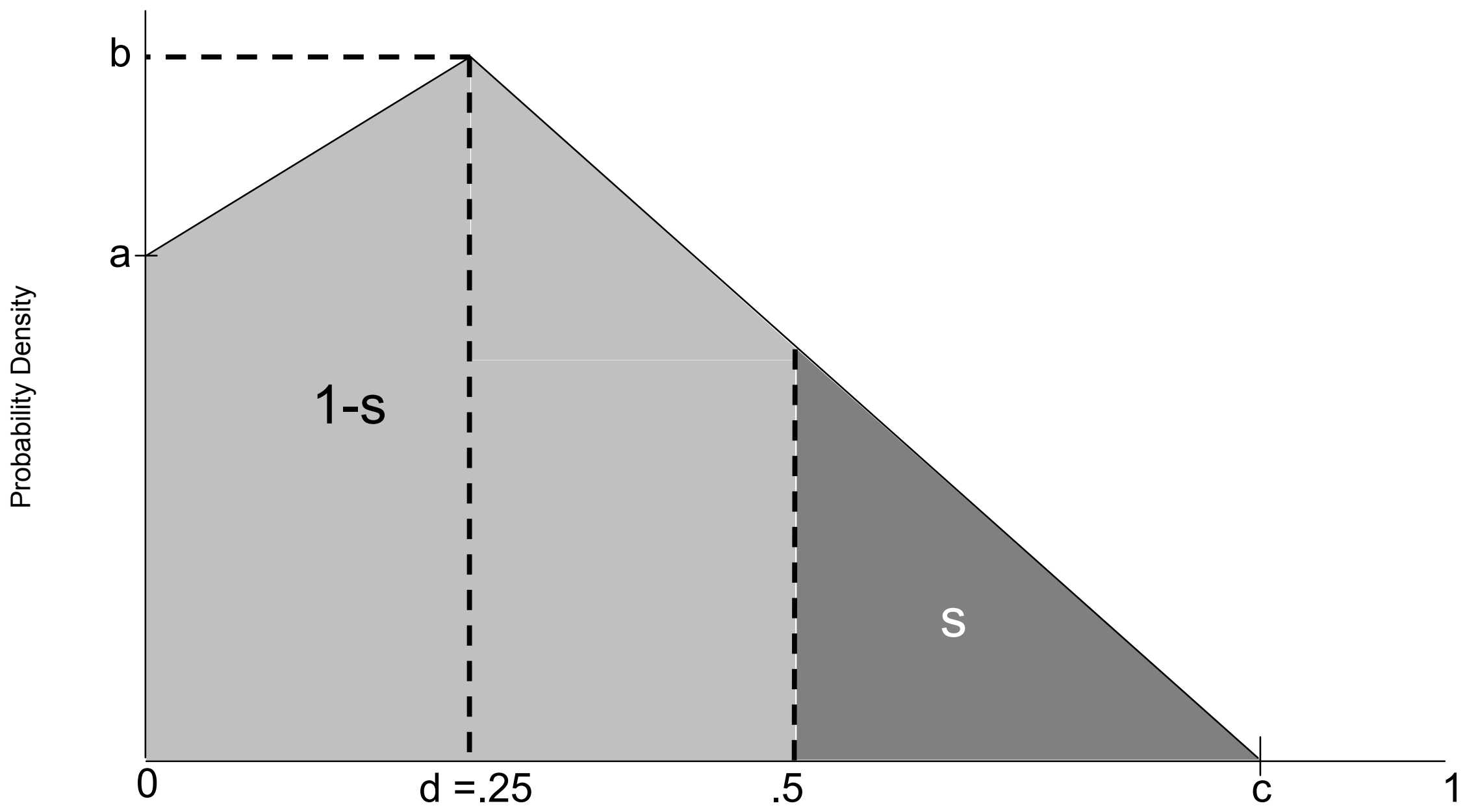

Marginal Propensity to Consume (m) 